\title{
Service users' experience of receiving bad news about their mental health
}

\begin{abstract}
\section{Background}

The breaking and receipt of bad news is little referred to in the mental health literature, particularly from a service user perspective.
\end{abstract}

\section{Aims}

This project aims to gain understanding of service users' experience of receiving good and bad news from mental health professionals.

\section{Method}

Ten semi-structured interviews were conducted in which mental health service users. recounted key moments when good or bad news was delivered to them and described the impact of that news on their psychological well being. Transcripts were analysed thematically.

\section{Results}

Significant news reported related to: diagnosis, treatment, being sectioned, discharge, admission, tribunal outcomes and career continuation. Diagnosis was perceived as a cause of confusion where a diagnosis is changed. The importance of trust in professionals and of adequate time and information was considered important in buffering the impact of potentially bad news. The technique of comparing a mental disorder to a physical disorder is 
not always helpful.

\section{Conclusions}

The delivery of bad news in mental health is more complex than a 'good or bad news' paradigm and it should be done in the context of a good therapeutic alliance. An individualised approach to delivering news about diagnosis is advocated.

\section{Declaration of interest}

This project was funded by the Nuffield Foundation.

Key words: good news, bad news, communication, diagnosis, information, therapeutic alliance, individualised approach 


\section{Service users' experience of receiving bad news about their mental health}

'I well believe it, to unwilling ears: that none love the messenger who brings bad news'

Sophocles

\section{Introduction}

There is a substantial literature regarding the breaking of bad news in relation to physical health, for example, in oncology and trauma services. In the introduction to one of the most influential texts in this area (Buckman 1992 p.1), a case history outlines the experience of Mark, who was admitted to hospital for prostatic biopsy. The senior surgeon stood by the door of the ward and told another patient in the room that he could go home. He then turned to Mark and said:

I'm glad to say you can also go home, but there's bad news as well - the biopsy showed cancer of the prostate.'

The surgeon then left the room. Mark's description of the negative impact of that experience was that 'nothing left him feeling so distraught and with so little idea how to cope'.

This example illustrates how the breaking of bad news, when it is not done well, can impact negatively on the well-being of recipients. Strategies and protocols have been proposed to enable practitioners to perform better in this area and there has been a significant improvement (see, for example, Baile et al 2000, Buckman 1992, Faulkner 1998). There has, however, been little explicit research attention to the experience of mental health service users and professionals. This paper reports findings from a qualitative pilot study which set out to begin to fill a research gap by exploring service users' experience of receiving good and bad news relating to their mental health. We discuss the background to the pilot project, method and findings. We consider three main implications from the project: the need to consider the impact and meaning of significant news for mental health service 
users; the importance of the therapeutic alliance in providing a platform to impart news ethically; and the need to further develop research in this area to underpin improvements in clinical practice.

\section{Background}

Buckman (1984) defines bad news as 'any news that drastically and negatively alters the patient's view of his or her future', and adds that the 'badness' of the news depends on what the recipient 'already knows or suspects about the future'. Faulkner (1998 p.2) defines bad news as 'information that could radically change the life of the recipient' and as 'information that the recipient does not wish to have'.

Bad news, therefore, can be defined as information that is perceived to be in some way unwelcome, as news that the recipient would rather not receive, or rather were not true, and which is likely to impact negatively on her/his life.

As illustrated in the example above, the literature in the field of cancer care makes the concept of bad news appear relatively straightforward, based on the assumption that a diagnosis of cancer is, invariably, bad news and that the way such news is imparted is therefore critical, in terms of the patient's psychological response and future wellbeing. There is no doubt that a diagnosis of cancer changes the patient's view of his or her future but the picture is more complicated today with many cancers being more often curable or at least being seen as long term conditions to be lived with, rather than requiring terminal care. For many people, receiving a firm diagnosis after weeks or months of illness may in part be good news, in so far as the patient now knows what the problem is and may now have a clear path of action to pursue. Nevertheless, a diagnosis of cancer remains a defining moment in many people's life, after which nothing is ever the same again.

The situation in mental health may have similarities but there is little literature on the nature or impact of receiving the news of a mental health diagnosis or strategies for delivering such 
news. There are important differences in making diagnoses between mental and physical ill health. The verification of physical illnesses such as cancer is by physical examination, and objective laboratory tests. There is generally an identifiable moment or situation when good or bad news will be shared, for example, when a patient attends for an out-patient appointment following the clinician's receipt of test results. Mental health diagnoses are less objective relying, for the most part, on professional judgement. Different models of mental distress render diagnosis in mental health contentious. Mental health practitioners unsympathetic to a medical or organic model (favouring, for example, non-medical models such as a social (stress) model, a cognitive behavioural, psychotherapeutic, family interactions or conspiratorial model - see Colombo 2008), may not attach a diagnostic label at all. Such fundamental differences are likely to influence the way news is constructed, delivered and received.

\begin{abstract}
Aims
This pilot project aims were: 1) to document service users' experiences of receiving bad news about their mental health (2) to explore the impact of that news upon them and (3) to list strategies used by professionals when breaking bad news.
\end{abstract}

\title{
Method
}

This qualitative study involved conducting ten semi structured interviews with ten mental health service users who had recent in-patient experiences. Six women and four men, with an age range from 22 to 69 years (mean age 46.3), and with experience of between one and nineteen in-patient admissions, agreed to participate. Nine of the participants were British and one was of African origin. Researchers visited two in-patient units and attended two community mental health team meetings, providing information and inviting participation from adult service users who had capacity, a recent (within the last year) in-patient admission and who were interested to participate. Two participants were recruited after 
discharge from one of the in-patient units and others with the help of community mental health professionals. We set out to interview ten service users and stopped recruiting when ten suitable participants had volunteered. One person recommended by a participant was excluded due to lack of capacity. An interview schedule was agreed and amended following two pilot Interviews (See Appendix 1). Interviews were conducted by AG, a mental health nurse and post-doctoral researcher, at a venue chosen by participants.

The grounded theory approach emphasises the inductive generation of theory from data (Glaser \& Strauss 1967). The grounding of theory in data is important in achieving the aim of supporting claims with credible evidence. The transcripts were read repeatedly, which sensitised us to the data. A line by line analysis of the data was carried and this enabled us to attend closely to the data and to what the data was telling us. All types of news that participants referred to was highlighted in the text, including participant's evaluatory statements about such news. Preliminary coding of the data from the first two interviews was undertaken in a project team meeting and an initial coding scheme was drawn up by the research team. The coding scheme involved news related to diagnosis; impact of news on self, family and friends; and strategies for disclosure of news, comparisons with physical illness. The team subsequently met to review the themes and reached final consensus. A search for deviant cases was carried out

\section{Results}

Participants' views of good and bad news: a preliminary typology

Significant news reported by participants related to information on the following topics: diagnosis of a mental health problem, treatment (medication and ECT), being sectioned, being discharged or admitted to an in-patient unit, the outcome of a mental health tribunal appealing against involuntary detention and career continuation. As well as being wideranging, few examples of news received were considered universally good or bad. For 
example, news relating to particular diagnoses, treatments and discharge considered good by some service users was considered bad by others. News was also subject to revision as it might be considered bad initially and good with the benefit of hindsight, for example, being sectioned and admitted to an in-patient unit was perceived as bad initially but considered good later when mental health had improved.

Specific examples of bad news related to being told that: a valued professional was leaving the service; they were unable to continue with higher education or return to work due to mental health problem; being transferred from the private sector to the NHS; and receipt of family news while an in-patient (for example, that a family member had committed suicide). Examples of good news related to: news that accommodation was available following discharge from an in-patient unit; sexual health (being given a negative HIV test result after fearing that he had become infected during a psychotic episode); and finance (being told of debts being written off as a result of mental health problems).

All participants referred to the receipt of a psychiatric diagnosis as significant news and we focus on this type of news. Key themes were: multiple and changing diagnosis and receipt of confusing and inadequate information. Five participants reported psychiatrists' changing diagnosis and giving more than one diagnosis in relation to good and bad news. This point is illustrated by the following example ${ }^{1}$ :

Well l'd been in hospital several times, beginning was depression and schizoaffectiveness, next time was schizophrenic, and [later] they said I was paranoid. (Edward)

Beth had received a diagnosis of bulimia and two further diagnoses:

All extracts have been anonymised. 
they also said I had unstable emotional borderline personality [...] I didn't get so much information of what it actually meant [...] I think that sort of covered things like self-harming, in part, acting without thinking. I think the diagnosis that covered was basics, like ways that I behave and that was a surprise as well because I hadn't heard of it, I didn't understand what it was [...] I think the psychotic depression has a harder impact on me because it sounded more scary, it frightened me a bit more. I think that was, had a bit more impact on me than borderline personality disorder. I can live with that, that's not there (Beth).

For one participant there was evidently some ambiguity around diagnosis and uncertainty as to whether being on medication or coming off it is a 'good' or 'bad' thing:

[My psychiatrist told me] "I've got good news for you and bad news for you. The good news is you don't need to take medication anymore, the bad news is" or was it the other way around? I can't remember which way. "The good news is you don't need to take medication anymore, the bad news is you've got a personality disorder so you no longer have 'bi-polar'.' So I actually hadn't a clue what this meant. (Anita)

Examples of changed and multiple diagnoses were, therefore, evident in our data. There is also evidence that the news may have been delivered with the 'good' or 'bad' label already identified by the person delivering the news, according to Anita. The 'news' delivered was complex and Anita describes how she was unaware of the consequences of having a personality disorder, she 'hadn't a clue' about this. Anita is describing how she was reclassified from being treatable with medication to untreatable.

Impact of receiving news

The impact of receiving news ranged from the experience of uncertainty and lack of understanding, to anxiety about stigma and extreme emotional reactions. The importance of being offered information in relation to potentially bad news was emphasised in two 
contrasting experiences:

I was given very little information. I was just told I had psychotic depression and that medication would help to stop the messages and get me back to health again. (Carol)

Yeah, but my consultant told me [about ECT] and gave me all the information and he handled it really, really well. He was very sensitive to, like, worries and issues. (Beth) Carol, then, felt that she had too little information whereas Beth felt that her psychiatrist had provided her with information about ECT in a sensitive manner.

The impact of good and bad news was described in terms of participants' future, emotional reactions and stigma. After receiving a diagnosis of bipolar disorder, Anita described feeling ‘as though I didn't have a future, it was so shocking as to know what was going to happen. I had no idea how it was going to affect my life'. Beth described an extreme emotional reaction after receiving news that her tribunal appeal had been rejected ('I felt suicidal'). Not all service users accepted that they had a mental health problem and, therefore, did not believe news of diagnosis and treatment:

Well, I won't take it [medication] because I don't think I need it. I don't want to be forced on medication if I don't need it, and I don't think I've got schizophrenia and I don't think l've got psychotic. All I've got is the dribbling which is the medication side effects - my head's OK. (Joan)

Participants discussed the role of stigma in relation to diagnoses suggesting why they might withhold, filter or censor information to family and others. Reflecting on sharing her diagnosis with friends Beth said:

I think it scared them (friends) quite a lot so I did lose quite a lot of contact [...] I wouldn't have told them the diagnosis [psychotic depression]. l'd have just told them 
depression. (Beth)

Mental health problems generally, it's a very big stigma. That's why, I mean, even my friends after years, they may know, I've told a few now I actually have bipolar, but when I was in hospital I didn't want anyone to visit me and for a long time I didn't actually tell them that's what I had (Anita).

Anita talked of her daughter's reluctance to tell her friends about Anita's bipolar disorder saying 'I can't say that'. News is bad, therefore, because it is stigmatising for participants' and, it is suggested, for participants' families resulting in their not sharing the news or limiting what they share with others.

Strategies for delivering news about diagnosis

The strategy of comparing a mental illness to a physical illness was reported to be employed by psychiatrists in imparting news of diagnosis to two users. One found it helpful:

He made me feel like, like there wasn't something wrong with me or anything, just that it was like an illness in a way like asthma is an illness that needs to be treated. Not like I'm a freak. (Beth)

Another participant did not find it helpful:

The doctor assessed you and said you were bipolar and you've got to take this medication basically because it's like having a heart condition or diabetes and it's not going to go away and you'll be on medication for the rest of your life. And I just couldn't accept it. [Int: Did comparison with physical illness help?] No, not at all. Because they said to me, if you were diabetic would you inject yourself with insulin everyday. I thought about it and I thought I wouldn't be able to (Anita).

The comparison with physical health may or may not, therefore, be helpful and this may 
depend on the nature of the comparison.

The significance of trust and of the giving of time to the development of a therapeutic relationship or alliance was highlighted by most service users. Harry puts it this way:

You have to be able to trust the psychiatrist, because if you don't trust the psychiatrist you will think that you are just being pumped up with medication [...] But that trust doesn't come by any means, by ward round or being in reception, that trust comes by the personality of the person you are dealing with, the personality of the psychiatrist. If they're open, if they embrace you, then you have greater trust [...] but if they take their time to sit down with you and build up a rapport [...] (Harry).

Beth provided a counter example, in relation to bad news, whereby night staff on an inpatient unit had reported her possession of drugs to the police without telling her that they were going to do this:

They should have explained they were going to inform the police [...] I should have been told because it was a real surprise waking up the next morning and finding a policeman outside your bedroom door [...] It was my right to know they'd informed the police, I thought I did have a right to know. I was quite angry with them to be quite honest because I understood it was my fault [...]. So I didn't feel I could talk to them if I was upset at night and it was the same night staff on. I didn't feel I could talk to them because I didn't trust them anymore (Beth).

Beth had a very positive relationship with her consultant however, in this situation, she lost trust in the night staff. This illustrates totally different experiences of news for the same service user related to the presence or absence of appropriate communication with her.

\section{Discussion}

Findings from this pilot study suggest common themes in relation to the receipt of news in 
mental health contexts. Although wide-ranging, it is not claimed that the types of news identified is exhaustive. One non-British participant, for example, suggested the importance of religious and cultural background in interpreting the news received. The disclosure of psychiatric diagnoses such as schizophrenia suggests that the participants' psychiatrists' model of mental disorder is a medical or organic model.

The verification and disclosure of a psychiatric diagnosis is a complex process with studies showing a mis-match between patient expectations and the practice of psychiatrists. For example, Shergill et al (1998) found less than half of inpatients stated they were informed of their diagnosis. Although most patients wished to know their diagnosis, psychiatrists were happier to use diagnoses such as depression, anxiety and substance misuse than a term like 'schizophrenia' (Paccaloni et al 2005). Alternatively they choose less stigmatising terms like "psychosis", "major mental illness", "mental breakdown" and "psychosis" (Clafferty et al 2001). The ethics of disclosing uncertain, changing and confusing psychiatric diagnoses is worthy of more critical analysis than we can engage in here.

Our data expand from the dilemma of disclosure / non or partial disclosure to the quality of the disclosure. The testimonies of our participants support a number of suggestions in the delivery of a diagnosis. First and foremost, it needs to be disclosed in the context of a trusting therapeutic relationship. Trustworthiness and respectfulness are important professional qualities or virtues (Banks and Gallagher 2009). Adequate time and information need to be given plus the chance to discuss its implications. Consideration needs to be given to the negative impact of the diagnosis and the issue of stigma needs to be addressed. The strategy of the comparison of a mental illness to a physical illness in this study may or may not be a successful way of achieving this. Hence there is a need for a careful individualised approach.

We have shown that service users reported poor communication, inadequate provision of information and the failure to listen. However other less predictable pitfalls can arise such as 
'overdiagnosis.' Here the use of multiple diagnoses may be technically correct according to a classification schedule but mean little to a service user other than cause confusion.

Alternatively switching diagnoses without explanation can be equally bewildering.

\section{Strengths and limitations}

This pilot study has succeeded in its aims of exploring the main themes of service users' experiences in relation to receiving bad news and has exposed the paradigm of disclosure of bad news in physical health as being of doubtful relevance to mental health. It succeeded in the use of in-depth interviews in order to present the service users' points of view. However, due to the small sample, it is possible that all types of experience may not have been identified and was not possible to quantify the types of experience. More specifically, as clinical encounters were not directly recorded, we could not address the potential of nondisclosure of diagnosis. In order to further investigate models of disclosure: for example the non-disclosure model, the full-disclosure model and the individualised disclosure model (DeValck et al 2001, Copp \& Field 2002), actual clinical encounters would need to be recorded and analysed. However, it was the case that the service users received one or more diagnosis consecutively or simultaneously. There was, therefore, disclosure of diagnosis although, some accounts suggest, inadequate disclosure of information about the nature and implications of the diagnosis.

\section{Conclusions - 'good news and bad news'}

In the introduction we referred to an example from Buckman relating to the experience of Mark. The seemingly insensitive surgeon shared the 'good news' and the 'bad news' and then walked away with no opportunity for discussion. Mark was, understandably, devastated but was left in no doubt as to what the 'good news' (going home) and 'bad news' (cancer diagnosis) was. As indicated by the experience of Anita in our study 'good news' and 'bad news' may be ambiguous and subjective. A psychiatric diagnosis in this case does not 
appear to fit so easily into the categories of good or bad. Previous research suggests that the way bad news is discussed impacts on satisfaction with medical care, adjustment afterwards and level of hopefulness (Baile et al 2000). Our findings suggest the importance of the relationships with professionals, which is supported by Chaplin et al (2007). An individualised approach that accommodates the diversity of service user experiences and perspectives. This pilot study has confirmed the need for further research in this area. 


\section{Appendix 1}

\section{Receiving Bad News about Your Mental Health}

Pilot Project

\section{Interview topics guide}

Purpose of interview: to find out your experience and views about receiving bad and good news about your mental health and to discover how health professionals might do this better.

Confidentiality: The interview will be tape recorded and transcribed. Only the project team will hear the tape or see the original transcript. Any reports based on this interview will ensure that your identity is not revealed.

\section{Topics}

1. Your background and involvement with mental health services.

2. Key moments when good news was received (ask interviewee to recount a particular situation e.g. 'last time this happened') - What was the news? Where were you at the time? Who broke the news? How did it make you feel? What, do you think, was the impact on your social well-being?

3. Key moments when bad news was received (ask interviewee to recount a particular situation e.g. 'last time this happened') - What was the news? Where were you at the time? Who broke the news? How did it make you feel? What, do you think, was the impact on your social well-being?

Further prompts will invite participants to consider being informed about the following issues: diagnosis, discharge, admission, detention under the MHA 1983.

4. Experience of sharing news about your mental health with others.

5. Recommendations for good practice in relation to sharing news with mental health service users.

\section{References}


Baile, W.F., Buckman, R., Lenzi, R., Glober, G., Beale, E.A. \& Kudelka, P. (2000) SPIKES A Six-Step Protocol for Delivering Bad News: Application to the Patient with Cancer. The Oncologist, 5, 302-311

Banks S. \& Gallagher A. (2009) Ethics in Professional Life: Virtues for Health and Social Care Palgrave/MacMillan

Buckman, R. (1992) How to Break Bad News: A Guide for Health-Care Professionals Papermac

Buckman, R. (1984) Breaking Bad News - Why Is It Still So Difficult? British Medical Journal, 288, 1597-1599

Chaplin, R., Lelliott, P., Quirk, A. \& Seale, C. (2007) Negotiating styles adopted by consultant psychiatrists when prescribing antipsychotics. Advances in Psychiatric Treatment, 13, 42-50

Clafferty R., McCabe W. and Brown K.W. (2001) Conspiracy of silence? Telling patients with schizophrenia their diagnosis. Psychiatric Bulletin, 25, 336-339

Colombo in Widdershoven et al 2008) - Ann G to add

Copp G. and Field, D. (2002) Open awareness and dying: the use of denial and acceptance as coping strategies by hospice patients. Nursing Times Research, 7, 118-27

De-Valck, C. (2001) Medical students' attitudes toward breaking bad news: An empirical test of the World Health Organisation Model. Psycho-Oncology,,10, 398-409

Faulkner, A. (1998) When the News is Bad: A Guide for Health Professionals Stanley Thornes (Publishers) Ltd, Cheltenham

Paccaloni, M., Moretti, F. \& Zimmerman, C. (2005) Giving information and involving in treatment: what do psychiatrists think? A review. Epidemiologia e Psichiatria Sociale, 14, 
$198-216$

Ptacek, J.T. \& Eberhardt, T.L (1996) Breaking bad news: a review of the literature. JAMA, $276,496-502$

Shergil,I S.S., Barker, D, \& Greenberg, M.(1998) Communication of psychiatric diagnosis.

Social Psychiatry and Psychiatric Epidemiology, 33, 32-38 